International Journal of Agriculture, Environment and Bioresearch

Vol. 07, No. 01; 2022

ISSN: $2456-8643$

\title{
BIFURCATION ANALYSIS OF PREDATOR-PREY IN AN ECOSYSTEM- PIED CROW CORVUS ALBUS AND STRAW-COLORED FRUIT BAT EIDOLON HELVUM ON THE UNIVERSITY OF ENERGY AND NATURAL RESOURCES, SUNYANI
}

\author{
${ }^{1}$ Opoku Ohemeng, M.; ${ }^{2 *}$ Agyei-Ohemeng, J., Adu Bright Yeboah ${ }^{3}$ \\ ${ }^{1}$ Department of Computer Science, Sunyani Technical University, Sunyani \\ ${ }^{2}$ Department of Ecotourism, Recreation and Hospitality, University of Energy and Natural Resources, Sunyani \\ ${ }^{3}$ Department of Anthropology, Calgary University. Canada. \\ https://doi.org/10.35410/IJAEB.2022.5702
}

\begin{abstract}
Estimation of wildlife population density is practically difficult because it requires considerable investment of resources and time. However, population indices are easier to obtain but they are mostly influenced by many unknown factors. Population indices and their relationships to actual counts are usually unclear. Since predators play very important role in the population dynamics of prey species it has been investigated in science that predators limit or regulate a prey population within an ecological system. This paper attempts to provide a foundation on predatorprey mathematical model using bifurcation analysis to describe the role that Pied crow, (Corvus albus) play in the population dynamics of Straw-colored fruit bats, (Eidolon helvum) on the University of Energy and Natural Resources campus in Sunyani. Bifurcation is used to analyze the changes in qualitative structure of differential equations. The analysis confirms that at the equilibrium point $(0,0)$, of the two populations are stable using center manifold theory, all other equilibrium points are unstable. It is therefore recommended that further application of the analysis can be used to analyze other known populations where there is a predator-prey relationship.
\end{abstract}

Keywords: Estimation, population, indices, bifurcation, mathematical model, center manifold.

\section{INTRODUCTION}

Accurate estimation of wildlife population density is practically difficult and requires considerable investment of resources and time. However, population indices are easier to obtain but they are mostly influenced by many unknown factors. Such indices and their relationships to actual counts are usually unclear. Wildlife ecologists often find interpretations of population indices difficult in situations where good information is needed quickly and at low cost.

Predation has been defined as individuals of one species living on individuals of another species in the trophic level in a food chain (Taylor 1984). Predators play very important role in the population dynamics of prey species and their dynamics have been investigated in science, yet whether or not predators limit or regulate a prey population remains an issue that needs further investigations within the ecological systems (e.g., Erlinge et al. 1984, Kidd and Lewis 1987, Newsome et al. 1989, Sinclair 1989, Sinclair et al. 1990, Messier 1991, 1994, Skogland 1991, Boutin 1992, Pech et al. 1992). 
Predation play a vital role in the dynamics of prey population, but the understanding and the long-term issues involved are controversial. To understand of predator-prey relationships is complicated by a multitude of factors in the environment and generally a lack of knowledge into most ecological systems that operate within the ecosystem under consideration. Besides predation, other factors may regulate or limit prey populations, and to some extent influence the degree to which predation affects prey populations. Generational effects may go unnoticed to create time lags that can affect the populations under study.

The process whereby predators feed on their preys has important implications on the impact upon their prey populations. In the case where predatory pressures on the prey population decrease, it will certainly occur with the numerical decline in predators when prey become too scarce to support the predators (Knowlton and Stoddart, 1992).

This paper attempts to provide a foundation on predator-prey mathematical model using bifurcation analysis to describe a study into the role that crows (Pied crow) play in the population dynamics of Straw-colored fruit bats, (Eidolon helvum) on the University of Energy and Natural Resources campus in Sunyani.

Bifurcation analysis is the study of changes in qualitative structure of differential equations. It occurs when a small change in the parameter (population of the predator) causes a change in the behavior of (prey) the solution.

For a differential equation system that contains parameters, a slight variation in a parameter has a significant impact on the solution

This model will try to explain the relationship that can suggest reasons why the debate over the influence of predators have on prey populations continues.

\section{STUDY AREA}

Sunyani is $400 \mathrm{~m}$ above sea level, and the University of Energy and Natural Resources is located in the Sunyani West District Assembly. The climate is characteristic of the tropical humid zone with two seasons, namely, harmattan and rainy season. Rainfall is bimodal with maximum occurring in May-June and September - October, (Meteorological Services, 2014). It lies between Latitudes $7^{\circ} 20^{\prime} \mathrm{N}$ and $7^{\circ} 05^{\prime} \mathrm{N}$ and Longitudes $2^{\circ} 30^{\prime} \mathrm{W}$ and $2^{\circ} 10^{\prime} \mathrm{W}$, and shares boundaries with Sunyani West District to the North, Dormaa District to the West, Asutifi District to the South and Tano North District to the East. The University of Energy and Natural Resources covers an area of 120 acres (48.564ha) lies along the Sunyani Berekum highway. It shares a boundary with the Regional Administration and the closest community is Fiapre towards Berekum. It is directly opposite the Seventh Day Adventist Secondary School and Hospital.

The campus is laid out with forest tree outgrowths, made up of indigenous tree species like Ceiba pentandra, Triplochiton scleroxylon, and exotic plant species like Eucalyptus grandifolia, Tectona grandis and Senna siamea (Agyei-Ohemeng, 2015). 


\section{METHODOLOGY}

In a predator- prey relationship we develop a mathematical model depicting this behavior in the ecosystem. B represents the Prey population, $\mathrm{H}$ represents the Predator population, R represents the Growth rate, $\mathrm{K}$ is the Carrying capacity, A shows the prey abundance, E represents the Conversion of Prey, D is the Quadratic closure coefficient and $\sigma$ is the Availability of tree coverage. Bifurcation analysis of a predator-prey population was used to do the analysis using a hypothetical population situation to express a stable state of the two populations in the ecosystem. Table 1 below gives a summary of the parameters and variables been used in the model with their interpretations.

Table 1: Parameters and variables used in the model

\begin{tabular}{|l|l|}
\hline Parameter & Interpretation \\
\hline B & Prey population size \\
\hline H & Predator population size \\
\hline R & Growth rate \\
\hline K & Carrying capacity \\
\hline C & Consumption rate \\
\hline A & Prey abundance \\
\hline E & Conversion of prey \\
\hline D & Quadratic closure coefficient \\
\hline$\sigma$ & Availability of tree coverage \\
\hline
\end{tabular}

\section{RESULTS}

The equations (1) and (2) below shows the dynamics between the predator-prey in the ecosystem.

$\frac{d B}{d t}=r B\left(1-\frac{B}{K}\right)-\left(\frac{C B^{2}}{A^{2}+B^{2}}\right) \sigma$

The above equation (1) shows the dynamics of the prey population.

$\frac{d H}{d t}=\frac{e c H B}{A^{2}+B^{2}}-D H^{2}$

The above equation (2) shows the dynamics of the predator population.

To begin with the analysis we solve for the equilibrium points. 
Solving we have:

$$
\begin{aligned}
& \left(\mathrm{B}_{1}{ }^{*}, \mathrm{H}_{1}{ }^{*}\right)=(0,0) \\
& \left(\mathrm{B}_{2}{ }^{*}, \mathrm{H}_{2}{ }^{*}\right)=\left(-A^{2} r k, \frac{\operatorname{Dec}\left(A^{2} r k\right)}{A^{2}\left[1+(r k)^{2}\right]}\right) \\
& \left(\mathrm{B}_{3}{ }^{*}, \mathrm{H}_{3}{ }^{*}\right)=\left(r A^{2}+k c r \sigma-r k A^{2}, \frac{\operatorname{Dec}\left[A^{2} r+k c \sigma+r A^{2} k\right]}{A^{2}\left[1+r\left[r A^{2}+2 k c \sigma-2 r A^{2} k-r k^{2} c \sigma-k^{2} c \sigma+r k^{2} A^{2}\right)\right]+k^{2} c^{2} \sigma}\right) \\
& \left(\mathrm{B}_{4}{ }^{*}, \mathrm{H}_{4}{ }^{*}\right)=\left(k-A^{2}-\frac{k c \sigma}{r}+k A^{2}, \frac{D e c\left[k-A^{2}-\frac{k c \sigma}{r}+k A^{2}\right]}{A^{2}+\left[k\left[k-\frac{2 k c \sigma}{r}+k\left(\frac{c \sigma}{r}\right)^{2}+A^{2}\left(-2+2 k+A^{2}+\frac{2 c \sigma}{r}-2 A^{2}-\frac{2 k c \sigma}{r}+k A^{2}\right)\right]\right.}\right)
\end{aligned}
$$

In finding the Jacobian of the above model equations, it gives:

$$
\mathrm{J}\left(\mathrm{B}^{*}, \mathrm{H}^{*}\right)=\left(\begin{array}{cc}
2 r B-r A^{2}-3 r B^{2}-k c B \sigma & 0 \\
2 e c H B+2 D H^{2} B & e c B^{2}-2 D H A^{2}+2 H B^{2}
\end{array}\right)
$$

For the first equilibrium point we get that

$\mathrm{J}(0,0)=\left(\begin{array}{cc}-r A^{2} & 0 \\ 0 & 0\end{array}\right)$

$|J(\mathrm{~B}, \mathrm{H})-\lambda I|=0$

$\mathrm{J}(0,0)=\left(\begin{array}{cc}-r A^{2}-\lambda & 0 \\ 0 & -\lambda\end{array}\right)=0$

$\left(-r A^{2}-\lambda\right)(-\lambda)=0$

The eigen values is given as

$\lambda_{1}=-r A^{2}$

$\lambda_{2}=0$

Since the Hartman globman's theory fails we use center manifold to determine the stability We let $\mathrm{F}(\mathrm{h})=\mathrm{B}(\mathrm{t})=\mathrm{ax}^{2}+\mathrm{bx}^{3}+\ldots$

$$
\frac{d B}{d t}=r(\mathrm{ax} 2+\mathrm{bx} 3+\ldots)\left(1-\frac{(\mathrm{ax} 2+\mathrm{bx} 3+\ldots)}{k}\right)-\left(\frac{c(\mathrm{ax} 2+\mathrm{bx} 3+\cdots)^{2}}{A^{2}+(\mathrm{ax} 2+\mathrm{bx} 3+\cdots)^{2}}\right) \sigma
$$

$$
\frac{d B}{d t}=\frac{\partial F}{\partial t} \cdot \frac{d B}{d t}
$$


Vol. 07, No. 01; 2022

ISSN: $2456-8643$

$\frac{\partial F}{\partial t}=2 a x+3 b x^{2}+\cdots$

$\frac{d B}{d t}=\left(2 a x+3 b x^{2}+\cdots\right)\left[r(\mathrm{ax} 2+\mathrm{bx} 3+\ldots)\left(1-\frac{(\mathrm{ax} 2+\mathrm{bx} 3+\ldots)}{k}\right)-\left(\frac{c(\mathrm{ax} 2+\mathrm{bx} 3+\cdots)^{2}}{A^{2}+(\mathrm{ax} 2+\mathrm{bx} 3+\cdots)^{2}}\right) \sigma\right]$

Comparing coefficients of (3) and (4) we get:

$$
\begin{aligned}
& a=\frac{-16 r}{66+22 r}, b=\frac{-8 r}{66+22 r} \\
& B(t)=-\frac{16 r}{66+22 r} x-\frac{8 r}{66+22 r} x^{2}-\cdots
\end{aligned}
$$

Putting (5) into (2) gives a center manifold

$\frac{d H}{d t}=\frac{e c H\left(-\frac{16 r}{66+22 r} x-\frac{8 r}{66+22 r} x^{2}-\cdots \quad\right)}{A^{2}+\left(-\frac{16 r}{66+22 r} x-\frac{8 r}{66+22 r} x^{2}-\cdots \quad\right)^{2}}-D H^{2}$

$\frac{d H}{d t}=-\left\{\frac{e c H\left(\frac{16 r}{66+22 r} x+\frac{8 r}{66+22 r} x^{2}+O x^{3} \cdots\right)}{A^{2}+\left(-\frac{16 r}{66+22 r} x-\frac{8 r}{66+22 r} x^{2}-\cdots\right)^{2}}+D H^{2}\right]$

$\frac{d H}{d t}<0$

Therefore, at the equilibrium point $\left(\mathrm{B}_{1}{ }^{*}, \mathrm{H}_{1}{ }^{*}\right)=(0,0)$, it is stable.

$\mathrm{J}\left(\mathrm{B}^{*}, \mathrm{H}^{*}\right)=\left(\begin{array}{cc}2 r B-r A^{2}-3 r B^{2}-k c B \sigma & 0 \\ 2 e c H B+2 D H^{2} B & e c B^{2}-2 D H A^{2}+2 H B^{2}\end{array}\right)$

Let $\left(\mathrm{B}_{2}{ }^{*}, \mathrm{H}_{2}{ }^{*}\right)=\left(-A^{2} r k, \frac{\operatorname{Dec}\left(A^{2} r k\right)}{A^{2}\left[1+(r k)^{2}\right]}\right)=(\Delta, \Gamma)$

$\mathrm{J}\left(\mathrm{B}_{2}{ }^{*}, \mathrm{H}_{2}{ }^{*}\right)=\left(\begin{array}{cc}2 r \Delta-r A^{2}-3 r \Delta^{2}-k c \Delta \sigma & 0 \\ 2 e c \Gamma \Delta+2 D \Gamma^{2} \Delta & e c \Delta^{2}-2 D \Gamma A^{2}+2 \Gamma \Delta^{2}\end{array}\right)$

$|J(\mathrm{~B}, \mathrm{H})-\lambda I|=0$

$\left(\begin{array}{cc}2 r \Delta-r A^{2}-3 r \Delta^{2}-k c \Delta \sigma-\lambda & 0 \\ 2 e c \Gamma \Delta+2 D \Gamma^{2} \Delta & e c \Delta^{2}-2 D \Gamma A^{2}+2 \Gamma \Delta^{2}-\lambda\end{array}\right)=0$

$\left(2 r \Delta-r A^{2}-3 r \Delta^{2}-k c \Delta \sigma-\lambda\right)\left(e c \Delta^{2}-2 D \Gamma A^{2}+2 \Gamma \Delta^{2}-\lambda\right)=0$. 
Vol. 07, No. 01;2022

ISSN: $2456-8643$

Let $\mathrm{Z}=2 r \Delta-r A^{2}-3 r \Delta^{2}-k c \Delta \sigma, Y=e c \Delta^{2}-2 D \Gamma A^{2}+2 \Gamma \Delta^{2}$

$(Z-\lambda)(Y-\lambda)=0$

$Z Y-Z \lambda-Y \lambda+\lambda^{2}=0$

$\lambda^{2}-(Z+Y) \lambda+Z Y=0$

$\lambda_{1}=\frac{-(Z+Y)+\sqrt{(Z+Y)^{2}-4 Z Y}}{2}$

$\lambda_{2}=\frac{-(Z+Y)-\sqrt{(Z+Y)^{2}-4 Z Y}}{2}$

For $Z^{2}+Y^{2}+2 X Y>4 Z Y$,

We get that:

$\left(e c\left(-A^{2} r k\right)^{2}+2 \Gamma\left(-A^{2} r k\right)^{2}\right)+\left(2 D \Gamma A^{2}\right)\left(r A^{2}+3 r\left(-A^{2} r k\right)^{2}+2 D \Gamma A^{2}\right)+$ $\left(2 \Gamma\left(-A^{2} r k\right)^{2}\right)\left(e c\left(-A^{2} r k\right)^{2}+2 \Gamma\left(-A^{2} r k\right)^{2}\right)$

$+$

$4 r A^{2}\left(e c\left(-A^{2} r k\right)^{2}+2 \Gamma\left(-A^{2} r k\right)^{2}\right)+12 r\left(-A^{2} r k\right)^{2}\left(e c\left(-A^{2} r k\right)^{2}+2 \Gamma\left(-A^{2} r k\right)^{2}\right)+$ $\left.2 \Gamma\left(-A^{2} r k\right)^{2}\right)+\left(2 A^{2} r k r\right)$

$\left(A^{2} r k k c \sigma\right)$

$\left(2 A^{2} r k r\right)+\left(r A^{2}\right)\left(+e c\left(-A^{2} r k\right)^{2}+2 \Gamma\left(-A^{2} r k\right)^{2}\right)+\left(3 r\left(-A^{2} r k\right)^{2}\right)\left(e c\left(-A^{2} r k\right)^{2}+\right.$ $\left.2 \Gamma\left(-A^{2} r k\right)^{2}\right)+\left(A^{2} r k k c \sigma\right)\left(e c\left(-A^{2} r k\right)^{2}+2 \Gamma\left(-A^{2} r k\right)^{2}\right)+\left(e c\left(-A^{2} r k\right)^{2}\right)\left(r A^{2}+\right.$ $\left.3 r\left(-A^{2} r k\right)^{2}+2 D \Gamma A^{2}\right)+\left(2 D \Gamma A^{2}\right)\left(e c\left(-A^{2} r k\right)^{2}+2 \Gamma\left(-A^{2} r k\right)^{2}\right)+\left(2 \Gamma\left(-A^{2} r k\right)^{2}\right)\left(r A^{2}+\right.$ $\left.3 r\left(-A^{2} r k\right)^{2}+2 D \Gamma A^{2}\right)+8 r A^{2}\left(D \Gamma A^{2}\right)+24 r\left(-A^{2} r k\right)^{2}\left(D \Gamma A^{2}\right)$ $>$ $\left(2 A^{2} r k r\right)\left(e c\left(-A^{2} r k\right)^{2}+2 \Gamma\left(-A^{2} r k\right)^{2}\right)+\left(r A^{2}\right)\left(A^{2} r k k c \sigma\right)+\left(3 r\left(-A^{2} r k\right)^{2}\right)\left(A^{2} r k k c \Delta \sigma\right)+$ $\left(k c A^{2} r k \sigma\right)\left(r A^{2}+3 r\left(-A^{2} r k\right)^{2}+2 D \Gamma A^{2}\right)+\left(e c\left(-A^{2} r k\right)^{2}\right)\left(2 A^{2} r k r\right)+\left(2 D \Gamma A^{2}\right)\left(2 A^{2} r k r+\right.$ $\left.A^{2} r k k c \sigma\right)+\left(2 \Gamma\left(-A^{2} r k\right)^{2}\right)\left(2 A^{2} r k r\right)$

$+16 r A^{2} r k\left(D \Gamma A^{2}\right)+4 A^{2} r k k c \sigma\left(e c\left(-A^{2} r k\right)^{2}\right)+$

$\left(2 A^{2} r k r\right)\left(r A^{2}+3 r\left(A^{2} r k\right)^{2}+2 D \Gamma A^{2}\right)+\left(r A^{2}\right)\left(2 A^{2} r k r\right) \quad+\left(3 r\left(A^{2} r k\right)^{2}\right)\left(\left(2 A^{2} r k r\right)+\right.$ $\left(A^{2} r k k c \sigma\right)\left(2 A^{2} r k r\right)$ $+\left(e c\left(-A^{2} r k\right)^{2}\right)\left(A^{2} r k k c \sigma\right)+\left(2 D \Gamma A^{2}\right)\left(2 A^{2} r k r\right)+\left(2 \Gamma\left(-A^{2} r k\right)^{2}\right)\left(A^{2} r k k c \sigma\right)+$ $\left(8 r A^{2} r k\right)\left(e c\left(-A^{2} r k\right)^{2}+2 \Gamma\left(A^{2} r k\right)^{2}\right)+8 A^{2} r k k c \sigma\left(D \Gamma A^{2}\right)$

Since the inequality hold, $\lambda_{1}$ and $\lambda_{2}$ will always be real numbers. Therefore either $\lambda_{1}>0, \lambda_{2}<0$ or $\lambda_{1}<0, \lambda_{2}>0$, the equilibrium point $\left(\mathrm{B}_{2}{ }^{*}, \mathrm{H}_{2}{ }^{*}\right)=\left(-A^{2} r k, \frac{\operatorname{Dec}\left(A^{2} r k\right)}{A^{2}\left[1+(r k)^{2}\right]}\right)$ will be an unstable point. 
$\mathrm{J}\left(\mathrm{B}^{*}, \mathrm{H}^{*}\right)=\left(\begin{array}{cc}2 r B-r A^{2}-3 r B^{2}-k c B \sigma & 0 \\ 2 e c H B+2 D H^{2} B & e c B^{2}-2 D H A^{2}+2 H B^{2}\end{array}\right)$

Let $\left(\mathrm{B}_{3}{ }^{*}, \quad \mathrm{H}_{3}{ }^{*}\right)=\left(r A^{2}+k c r \sigma-r k A^{2}, \frac{\operatorname{Dec}\left[A^{2} r+k c \sigma+r A^{2} k\right]}{A^{2}\left[1+r\left[r A^{2}+2 k c \sigma-2 r A^{2} k-r k^{2} c \sigma-k^{2} c \sigma+r k^{2} A^{2}\right)\right]+k^{2} c^{2} \sigma}\right)=$ $(\Pi, Д)$

$\mathrm{J}\left(\mathrm{B}_{3}{ }^{*}, \mathrm{H}_{3}{ }^{*}\right)=\left(\begin{array}{c}2 r \Pi-r A^{2}-3 r \Pi^{2}-k c \Pi \sigma \\ 2 e c Д \Pi+2 D Д^{2} \Pi\end{array} \quad \begin{array}{c}0 \\ e c \Pi^{2}-2 D Д A^{2}+2 д \Pi^{2}\end{array}\right)$

$|J(\mathrm{~B}, \mathrm{H})-\lambda I|=0$

$\left(\begin{array}{cc}2 r \Pi-r A^{2}-3 r \Pi^{2}-k c \Pi \sigma-\lambda & 0 \\ 2 e c д \Pi+2 D Д^{2} \Pi & e c \Pi^{2}-2 D Д A^{2}+2 д \Pi^{2}-\lambda\end{array}\right)=0$

$\left(2 r \Pi-r A^{2}-3 r \Pi^{2}-k c \Pi \sigma-\lambda\right)\left(e c \Pi^{2}-2 D Д A^{2}+2 Д \Pi^{2}-\lambda\right)=0$.

Let $\left(\mathrm{B}_{4}{ }^{*}, \mathrm{H}_{4}{ }^{*}\right)=\left(k-A^{2}-\frac{k c \sigma}{r}+k A^{2}, \frac{D e c\left[k-A^{2}-\frac{k c \sigma}{r}+k A^{2}\right]}{A^{2}+\left\{k\left[k-\frac{2 k c \sigma}{r}+k\left(\frac{c \sigma}{r}\right)^{2}+A^{2}\left\{\left(-2+2 k+A^{2}+\frac{2 c \sigma}{r}-2 A^{2}-\frac{2 k c \sigma}{r}+k A^{2}\right)\right]\right]\right.}\right)=$ $(\mathrm{M}, \mathrm{N})$

$\mathrm{J}\left(\mathrm{B}_{4}{ }^{*}, \mathrm{H}_{4}{ }^{*}\right)=\left(\begin{array}{cc}2 r M-r A^{2}-3 r B M^{2}-k c M \sigma & 0 \\ 2 e c N M+2 D N^{2} M & e c M^{2}-2 D N A^{2}+2 N M^{2}\end{array}\right)$

$|J(\mathrm{~B}, \mathrm{H})-\lambda I|=0$

$\left(\begin{array}{cc}2 r M-r A^{2}-3 r B M^{2}-k c M \sigma-\lambda & 0 \\ 2 e c N M+2 D N^{2} M & e c M^{2}-2 D N A^{2}+2 N M^{2}-\lambda\end{array}\right)=0$

$\left(2 r M-r A^{2}-3 r B M^{2}-k c M \sigma-\lambda\right)\left(e c M^{2}-2 D N A^{2}+2 N M^{2}-\lambda\right)=0$

Solving (7) and (8) follows the same argument as (6) above.

Since the eigen values from (7) and (8) will result in either $\lambda_{1}>0, \lambda_{2}<0$ or $\lambda_{1}<0, \lambda_{2}>0$, the equilibrium of (7) and (8) will be unstable.

Therefore (7) and (8) are unstable.

\section{DISCUSSION}

The University of Energy and Natural Resources in Sunyani, is unique in that it has a large resident fruit bat colony on the campus. Despite the presence of the bats on the site since 2008, ecological studies conducted by the author, indicate that the population of the bats fluctuate monthly, and this has had a telling effect on the trees on the campus and its concomitant nuisance on students and staff on campus. The ecological studies show that there are bats present on the campus throughout the year (Agyei-Ohemeng 2013; 2015; 2016). 
Crows are the main predators on these bats, preying on their young and feeble bats. The crow populations are high during the months of April and June when the bats have given birth. On the campus of UENR, there are a population of Straw-colored fruit bats, amazingly their only predators are crows, Pied crow. Bat predation was excellent due to the absence of foliage where a group of eight crows perched approximately $10 \mathrm{~m}$ high, at the edge of the woods during my personal observation. Based on size and relative species abundances of bats, the bats flew jerking in different directions, approximately 5-7 $\mathrm{m}$ above the ground, eluding capture by $1-3$ crows that chase them at a time. Each time crows approached closely the bat dropped in altitude, effectively evading them. However, the offtake, in terms of predation is high on the weak and fragile young ones who are mostly too weak to fly.

Bats have an amazing ability to use radar to avoid obstacles as well as predators, but there are some predators who have them figured out. Some crow swoop suddenly out of nowhere, grabbing bats in flight before the bats can react, however, others wait until daylight when the bats are sleeping to attack them in their roosts picking the young and weak ones in the population. In all, the actions that tend to limit the populations (Skogland 1991) such as any mortality factor that can reduce the rate of population increase (Ballard et al. 2001) can stabilize the population. Numerically, increase in population numbers can respond in a state where predator numbers can increase in response to prey abundance which may be from reproduction or immigration (Knowlton and Stoddart 1992).

In these two systems of equations..... (1) and...... (2), model parameters are allowed to vary to see how the model solution may change. Parameters that affect the prey (bat) population and predator (crow) population are made to vary to see how this may affect the solution of the system of equations.

Hartman-Grobman was used to conclude on the stability based on the nature of the eigen values of the system. For the equilibrium point at $(0,0)$ the center manifold theory was applied since the Hartman-Grobman failed. It confirmed that at the equilibrium point $(0,0)$, the system was stable since $\lambda_{1}<0$ and $\lambda_{2}<0$. The equilibrium points for $\left(\mathrm{B}_{2}, \mathrm{H}_{2}\right)$ to $\left(\mathrm{B}_{4}, \mathrm{H}_{4}\right)$ gave eigen values as either $\lambda_{1}<0, \lambda_{2}>0$ or $\lambda_{1}>0, \lambda_{2}<0$. This concludes the system as unstable at these equilibrium points.

\section{CONCLUSION}

The stability analysis shows that the system will only be stable at the point when $\mathrm{B}^{*}=0, \mathrm{H}^{*}=0$. At all other equilibrium points the system will be unstable. The population of the prey (bats) will be in abundance causing the population of the crows to decrease. This can be confirmed on the University of Energy and Natural Resources campus Sunyani where the increasing population of prey (Bats) is causing the decrease in the population of predators (Pied Crows).

\section{RECOMMENDATION}

It is therefore recommended that bifurcation analysis can be applied in any predator prey relationship to predict stability in an ecosystem. 
Vol. 07, No. 01; 2022

ISSN: $2456-8643$

\section{REFERENCES}

Agyei-Ohemeng J. (2015), Aspects of the Ecology of Fruit Bat (Eidolon helvum) in the University of Energy and Natural Resources, Sunyani MPhil Thesis, Kwame Nkrumah University of Science and Technology, Kumasi, Ghana.

Agyei-Ohemeng, J., (2013), Bats: Ghana's best-kept wildlife secret. Daily Graphic,

Agyei-Ohemeng, J. \& Danquah, E., (2016), The contribution of fruit bats, Eidolon helvum, to biodiversity on the University of Energy and Natural Resources' campus, Sunyani, Ghana. Journal of Natural Sciences Research 6(8): 74-82.

Ballard, W. B., D. Lutz, T. W. Keegan, L. H. Carpenter, and J. C. deVos, Jr. (2001). Deer-predator relationships: a review of recent North American studies with emphasis on mule and black-tailed deer. Wildlife Society Bulletin 29:(in press).

Boutin. S. (1992). Predation and moose population dynamics: critique. Journal of Wildlife Management 56:116-127.

Erlinge, S., G. Gbransson, G. Hogstedt, G. Jansson, 0. Liberg, J. Loman, I. N. Nilsson, T. von Schantz, and M. Sylvkn. (1984). Can vertebrate predators regulate their prey? American Naturalist 23:125-133.

Kidd, N. A. C., and G. B. Lewis. (1987). Can vertebrate predators regulate their prey? A reply. American Naturalist 130:44S-453.

Knowlton, F. F., and L. C. Stoddart. (1992). Some observations from two coyote-prey studies. Pages 101-121 in A. H. Boer, editor. Ecology and management of the eastern coyote. University of New Brunswick, Fredericton.

Messier, F. (1991). The significance of limiting and regulating factors on the demography of moose and white-tailed deer. Journal of Animal Ecology 60:377-393.

Messier. F. (1994). Ungulate population models with predation: a case study with the North American moose. Ecology 75:478- 488.

Meteorological Services Data. (2014). Sunyani.

Newsome, A. E., I. Parer, and P. C. Catling. *(1989). Prolonged prey suppression by carnivores predator-removal experiments. Oecologia (Berlin) 78:458-467.

Pech, R. P., A. R. E. Sinclair, A. E. Newsome, and P. C. Catling. (1992). Limits to predator regulation of rabbits in Australia: evidence from predator-removal experiments. Oecologia (Berlin) 89:102- 112.

Sinclair, A. R. E. (1989). Population regulation in animals. Pages 197-241 in J. M. Cherrett, editor. Ecological concepts. Blackwell. Oxford.

Sinclair, A. R. E., P. D. Olsen, and T. D. Redhead. (1990). Can predators regulate small mammal populations? Evidence from house mouse outbreaks in Australia. Oikos 59:382-392.

Skogland, T. (1985). The effects of density dependent resource limitation on the demography of wild reindeer. Journal of Animal Ecology 54:359-374.

Skogland, T. (1991). What are the effects of predators on large ungulate populations? Oikos 61:401-411.

Taylor, R. J. (1984). Predation. Chapman and Hall, New York. 